Rabaska

Revue d'ethnologie de l'Amérique française

\title{
Naviguer en canot à glace, un patrimoine immatériel
}

Volume 11, 2013

URI : https://id.erudit.org/iderudit/1018521ar

DOI : https://doi.org/10.7202/1018521ar

Aller au sommaire du numéro

Éditeur(s)

Société québécoise d'ethnologie

ISSN

1703-7433 (imprimé)

1916-7350 (numérique)

Découvrir la revue

Citer ce document

(2013). Naviguer en canot à glace, un patrimoine immatériel. Rabaska, 11,

135-135. https://doi.org/10.7202/1018521ar d'utilisation que vous pouvez consulter en ligne.

https://apropos.erudit.org/fr/usagers/politique-dutilisation/ 


\section{Place publique}

Points de vue / livre

\section{Naviguer en canot à glace, un patrimoine immatériel}

En février 2012, paraissait un ouvrage tiré d'une étude soutenue en partie par le ministère de la Culture et des communications du Québec et la Ville de Québec, et publiée aux Éditions GiD par les soins de la Société québécoise d'ethnologie (SQE) : Naviguer en canot à glace. Un patrimoine immatériel par Richard Lavoie avec la collaboration de Bernard Genest. Comme la SQE l'annonçait dans son rapport annuel pour 2012, elle a déposé en février 2013, selon les dispositions de la nouvelle Loi sur le patrimoine culturel du Québec (2011) une demande officielle de désignation de la traversée du fleuve en canot à glace entre Québec et Lévis comme élément du patrimoine immatériel. La revue Rabaska a demandé à quatre experts d'examiner le beau livre qui a servi de base à cette proposition de statut et de donner leur point de vue. Ce sont Virgil Benoit, professeur de français à l'Université du North-Dakota et spécialiste des communautés canadiennes-françaises du centre-ouest des États-Unis, Pierre Lahoud, photographe de Québec, historien de formation et spécialiste en patrimoine, l'ethnologue Dominique Sarny, directeur fondateur de l'Institut français et professeur au Département de français à l'Université de Régina, et Michel Valière, enseignant, ethnologue de la région PoitouCharentes et associé à l'Université de Poitiers, en France.

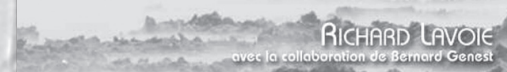

Wha (c) 0$)^{2}$ (P) Un potrimotic immarsic|

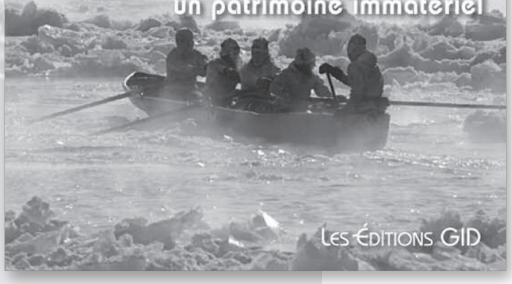

Richard Lavoie avec la collaboration de Bernard Genest Naviguer en canot à glace, un patrimoine immatériel Québec, Les Éditions GID, 2012, 236 p. ill. ISBN 978-2-89634-111-5 